\title{
Description of Emergency Medical Services, treatment of cardiac arrest patients and cardiac arrest registries in Europe
}

Ingvild B. M. Tjelmeland ${ }^{1,2,3^{*}}$ (D), Siobhan Masterson ${ }^{4}$, Johan Herlitz ${ }^{5,6}$, Jan Wnent ${ }^{1,7,8}$, Leo Bossaert ${ }^{6,9}$, Fernando Rosell-Ortiz ${ }^{6,10}$, Kristin Alm-Kruse ${ }^{3,11}$, Berthold Bein ${ }^{12,13}$, Gisela Lilja ${ }^{14}$, Jan-Thorsten Gräsner ${ }^{1,6,7}$ and on behalf of GL2020 Epidemiology group and participating countries

\begin{abstract}
Background: Variation in the incidence, survival rate and factors associated with survival after cardiac arrest in Europe is reported. Some studies have tried to fill the knowledge gap regarding the epidemiology of out-ofhospital cardiac arrest in Europe but were unable to identify reasons for the reported differences. Therefore, the purpose of this study was to describe European Emergency Medical Systems, particularly from the perspective of country and ambulance service characteristics, cardiac arrest identification, dispatch, treatment, and monitoring.

Methods: An online questionnaire with 51 questions about ambulance and dispatch characteristics, on-scene management of cardiac arrest and the availability and dataset in cardiac arrest registries, was sent to all national coordinators who participated in the European Registry of Cardiac Arrest studies. In addition, individual invitations were sent to the remaining European countries.

Results: Participants from 28 European countries responded to the questionnaire. Results were combined with official information on population density. Overall, the number of Emergency Medical Service missions, level of training of personnel, availability of Helicopter Emergency Medical Services and the involvement of first responders varied across and within countries. There were similarities in team training, availability of key resuscitation equipment and permission for ongoing performance of cardiopulmonary resuscitation during transported. The quality of reporting to cardiac arrest registries varied, as well as the data availability in the registries.
\end{abstract}

Conclusions: Throughout Europe there are important differences in Emergency Medical Service systems and the response to out-of-hospital cardiac arrest. Explaining these differences is complicated due to significant variation in how variables are reported to and used in registries.

Keywords: Emergency Medical Services (EMS), Out-of-hospital cardiac arrest, Cardiac arrest registries, Dispatch, Epidemiology of cardiac arrest

\footnotetext{
* Correspondence: ingvild@nakos.no

${ }^{1}$ Institute for Emergency Medicine, University-Hospital Schleswig-Holstein, Arnold-Heller-Str. 3, 24105 Kiel, Germany

2Division of Prehospital Services, Oslo University Hospital, Oslo, Norway

Full list of author information is available at the end of the article
}

(c) The Author(s). 2020 Open Access This article is licensed under a Creative Commons Attribution 4.0 International License, which permits use, sharing, adaptation, distribution and reproduction in any medium or format, as long as you give appropriate credit to the original author(s) and the source, provide a link to the Creative Commons licence, and indicate if changes were made. The images or other third party material in this article are included in the article's Creative Commons licence, unless indicated otherwise in a credit line to the material. If material is not included in the article's Creative Commons licence and your intended use is not permitted by statutory regulation or exceeds the permitted use, you will need to obtain permission directly from the copyright holder. To view a copy of this licence, visit http://creativecommons.org/licenses/by/4.0/. The Creative Commons Public Domain Dedication waiver (http://creativecommons.org/publicdomain/zero/1.0/) applies to the data made available in this article, unless otherwise stated in a credit line to the data. 


\section{Background}

Epidemiology of cardiac arrest and the systems that care for out-of-hospital cardiac arrest (OHCA) patients have been described in many studies. Regional and inter-country variation in survival is a consistent finding in epidemiological studies. In a study from the Resuscitation Outcomes Consortium (ROC), variation between sites was 4.7 to $20 \%$ [1]. In 2015, across the seven ambulance services that contribute to the Australian and New Zealand Resuscitation Outcomes Consortium, survival ranged from 9 to 17\% [2]. Similarly, from 2009 to 2012, the Pan Asian Resuscitation Outcomes Study (PAROS) observed survival ranging from 0.5 to $8.5 \%$ across seven countries [3]. In Europe, the European Registry of Cardiac Arrests (EuReCa) studies showed that between-country OHCA survival ranged from 1.1 to $31 \%$ over a 1 -month period in 2014 [4], and from 0 to $18 \%$ over a 3-month period in 2017 [5].

Identifying the factors that contribute to this variation in OHCA survival is important. The consensus-based Utstein template provides a dataset of patient-level variables associated with survival [6]. Some factors that influence survival are well known i.e. witnessed collapse, bystander cardiopulmonary resuscitation, initial shockable cardiac arrest rhythm and achieved return of spontaneous circulation (ROSC) [7]. It has been estimated in a single city (Toronto) that patient-level Utstein variables accounted for $89 \%$ of variability in OHCA survival [8]. In a study from ROC, it was estimated that Utstein variables accounted for $72 \%$ of variability across North American sites [9]. However, in a study using international data from 232 Emergency Medical Services (EMS) agencies in 12 countries, the proportion of survival variability accounted for by Utstein variables fell to $51 \%$ [10]. The more international the study sites, the greater the variation in interpretation, system, organisation and culture. Hence, the less variation that is explained by patientlevel Utstein variables.

Variability in EMS organisation is a common theme across international cardiac arrest registries and epistries [11-14]. It is likely that differences in EMS systems in Europe account for at least some of the differences in OHCA survival. Other factors that might account for the observed variability in survival after OHCA are differences in the links in the chain of survival e.g. the first link (early call for help) [15], or in the fourth link (post-resuscitation care) [16]. Development of different "first responder systems" may also explain part of the variability in survival [17].

In the last European-wide study, EuReCa TWO, the mean incidence rate of started resuscitations was 56 per 100,000 inhabitants per year, ranging from 27 to 91 per 100,000 inhabitants per year [5]. This wide range in national incidence estimates may have been caused by differences in how key variables were interpreted. However, much of this variation is likely to be attributable to patient and system level differences. To date, there has been no comprehensive description of EMS systems in Europe. Therefore, the objective of this study is to describe European EMS systems, particularly from the perspective of ambulance service characteristics, cardiac arrest identification, dispatch, treatment, and monitoring.

\section{Methods}

A structured questionnaire was developed through a review of published literature on previous international ambulance surveys [11-14, 18] and by consensus among members of the European Resuscitation Council (ERC) Guidelines 2020 Epidemiology Writing Group (Writing Group). The questionnaire was designed to investigate the following five categories: (Additional file 1; EMS survey):

1. Country and EMS baseline characteristics

2. Ambulance Service characteristics

3. Dispatch characteristics

4. On-Scene Management of Out-of-Hospital Cardiac Arrest by the EMS

5. Cardiac Arrest Registries

The survey was piloted with the members of the Writing Group. The questionnaire was shared with participants using the online tool Questback, licensed to Oslo University Hospital. All information is stored on an approved area at Oslo University Hospital.

The survey was distributed between October 2019 and January 2020. All national coordinators of the EuReCa ONE or EuReCa TWO studies were asked to participate $(n=31)$. Representatives from other European countries were invited to participate using the ERC network and the individual networks of the Writing Group $(n=3)$. In total the survey was sent to 34 different countries. Participants were asked to provide information for the entire country.

After completion of the survey, results were returned to each participant, who was asked to validate responses with at least one other national expert. Countries that did not confirm their response were excluded from the survey. In case of inconsistencies or critical missing data, participants were again contacted to maximise data quality. After all the data had been merged into a result section, the tables were again shared with the participants, who then confirmed the results. All participants were asked for consent to be acknowledged in publications and reports. Participants were entitled to withdraw from the study at any time up to submission of the article.

Descriptive analysis of data was carried out using Statistical Package for Social Sciences (SPSS, Inc., IL, USA) version 23. Results are presented as frequencies and proportions.

\section{Results}

Country information and baseline characteristics

Survey responses from 33 out of 39 (85\%) respondents were received. Three responses were excluded as results 
related to only one region $(n=2)$ or validation of results was not received $(n=1)$. For the United Kingdom, separate answers were received for England, Scotland and Northern Ireland and the answers were merged. A total of 28 countries were included in the analysis.

For participating countries, national populations varied from 375,000 in Iceland to over 83 million in Germany [19]. Population density ranged from 3.6 to almost 510 population $/ \mathrm{km}^{2}$ (Fig. 1). Data on the number of EMS missions per 1000 inhabitants per year were available for 19 countries and varied from 12 in France to 268 in Lithuania. In $75 \%$ of countries the EMS was described as publicly funded. Germany had the greatest number of hospitals per million inhabitants while Finland had the lowest (23 vs 3.6 respectively). Only Albania and Cyprus did not operate bypass protocols to bring patients directly to a Percutaneous Coronary Intervention (PCI)capable hospital. The majority of respondents $(n=25)$ also reported that there were "Cardiac Arrest" hospitals in their country i.e. hospitals capable of providing all of the following post-resuscitation interventions: 24/7 primary PCI, targeted temperature management and neuro-prognostication. Data on the median response times for urban and rural areas is presented in Table 1.

\section{Ambulance service characteristics}

In 15 countries, the majority of EMS personnel were reported as paramedics or Emergency Medical Technicians (EMTs) with at least 2 years of specialist training (Fig. 2). It was reported that all ambulance personnel were trained in Advanced Life Support (ALS) in 19 countries (i.e. at least ERC ALS level or similar), and at least some were trained in the remaining countries. In 12 countries, non-physician ambulance personnel were allowed to perform ALS procedures in the absence of a physician (see Table 2).

A Helicopter EMS (HEMS) was available in 24 countries. Cyprus, Iceland, Lithuania and Serbia reported that

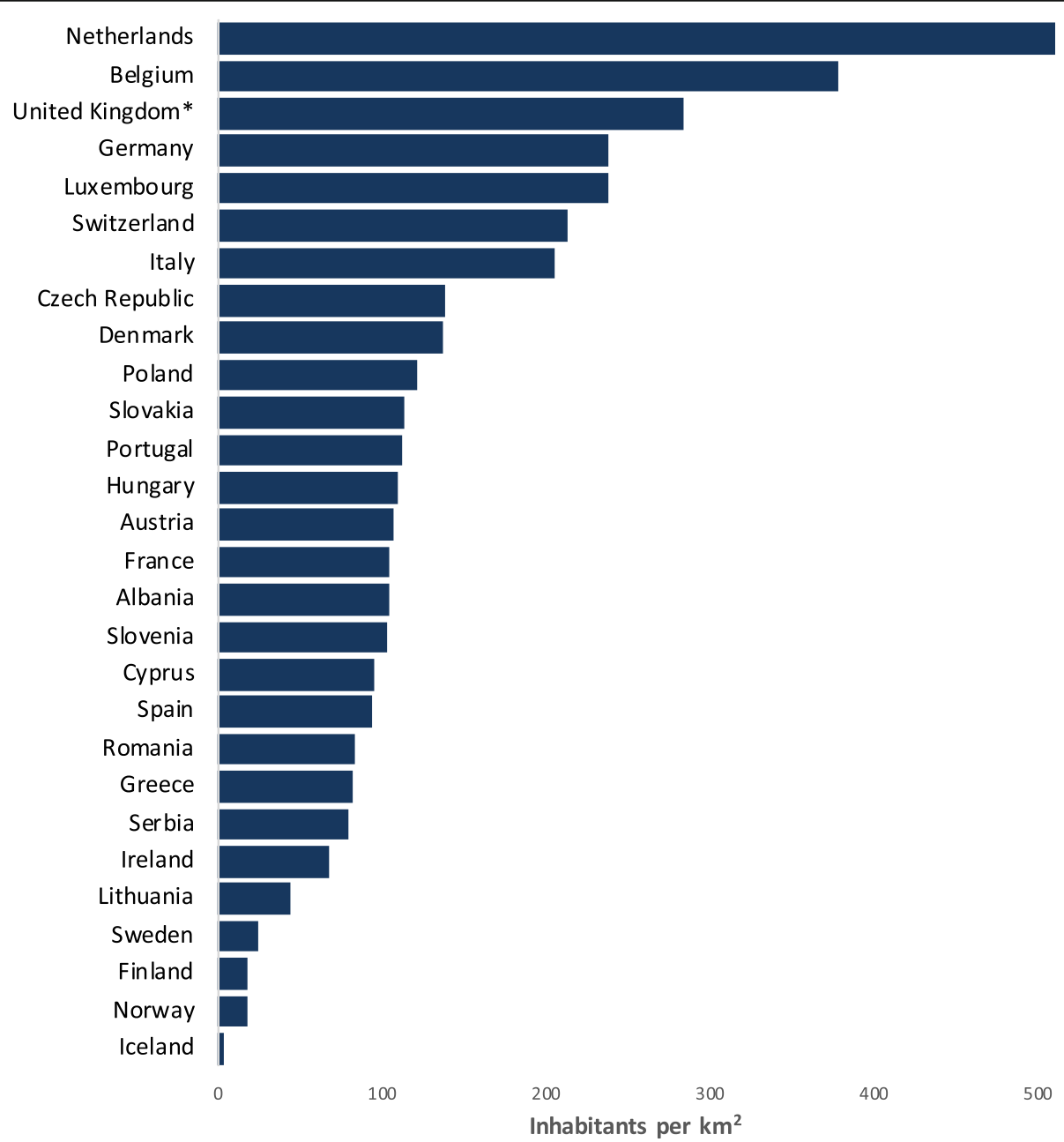

Fig. 1 Population per $\mathrm{km}^{2}$ in Countries Surveyed. Legend: Population density calculated per $\mathrm{km}^{2}$ in relation to total population of the country. The numbers are from the official webpage of the European Union, Europa.eu. * Unite Kingdom excluding Wales 
Table 1 Baseline characteristics of participating countries

\begin{tabular}{|c|c|c|c|c|c|c|c|c|}
\hline Country & Population & $\begin{array}{l}\text { EMS Missions } \\
\text { per } 1000 \\
\text { inhabitants }\end{array}$ & $\begin{array}{l}\text { Public or } \\
\text { Private EMS } \\
\text { funding? }\end{array}$ & $\begin{array}{l}\text { Hospitals } \\
\text { per million } \\
\text { population }\end{array}$ & $\begin{array}{l}\text { "Cardiac } \\
\text { Arrest" } \\
\text { hospitals }\end{array}$ & $\begin{array}{l}\mathrm{PCl} \\
\text { bypass } \\
\text { protocol }\end{array}$ & $\begin{array}{l}\text { Rural areas - median } \\
\text { ambulance response } \\
\text { time }<10 \text { min? }\end{array}$ & $\begin{array}{l}\text { Urban - median } \\
\text { ambulance } \\
\text { response } \\
\text { time }<10 \mathrm{~min} \text { ? }\end{array}$ \\
\hline Albania & $2,862,400$ & & Public & & Some areas & No & Some areas & Some areas \\
\hline Austria & $8,858,800$ & & Public & 10.4 & All areas & Yes & Some areas & Some areas \\
\hline Belgium & $11,467,900$ & 77.0 & Public and private & 10.9 & All areas & Yes & Some areas & All areas \\
\hline Cyprus & 875,900 & 62.8 & Public & 8.0 & All areas & No & Some areas & Some areas \\
\hline Czech Republic & $10,649,800$ & 103.9 & Public & & Some areas & Yes & Some areas & All areas \\
\hline Denmark & $5,806,100$ & 68.9 & Public & 3.8 & Some areas & Yes & Some areas & All areas \\
\hline Finland & $5,517,900$ & 140.1 & Public & 3.6 & Some areas & Yes & Some areas & Some areas \\
\hline France & $67,028,000$ & 11.9 & Public & 9.8 & Some areas & Yes & No & Some areas \\
\hline Germany & $83,019,200$ & 172.2 & Public & 22.9 & Some areas & Yes & Some areas & Some areas \\
\hline Greece & $10,722,300$ & & Public & & None & Yes & Some areas & Some areas \\
\hline Hungary & $9,772,800$ & & Public & 5.9 & Some areas & Yes & Some areas & Some areas \\
\hline Iceland & 357,000 & 117.6 & Public & 14.0 & Some areas & Yes & Some areas & All areas \\
\hline Ireland & $4,693,460$ & 95.9 & Public & 6.2 & Some areas & Yes & No & Some areas \\
\hline Italy & $60,359,500$ & & Public & 4.7 & Some areas & Yes & Some areas & All areas \\
\hline Lithuania & $2,794,200$ & 268.4 & Public and private & 14.3 & None & Yes & No & No \\
\hline Luxembourg & 613,900 & 72.5 & Public & 4.9 & Some areas & Yes & Some areas & All areas \\
\hline Netherlands & $17,282,200$ & 57.6 & Public and private & 5.0 & All areas & Yes & Some areas & Some areas \\
\hline Norway & $5,323,933$ & 136.2 & Public & 9.4 & Some areas & Yes & Some areas & All areas \\
\hline Poland & $37,972,800$ & & Public & 8.6 & Some areas & Yes & No & All areas \\
\hline Portugal & $10,276,600$ & 114.2 & Public & 4.3 & Some areas & Yes & No & Some areas \\
\hline Romania & $19,401,700$ & 172.1 & Public and private & 6.7 & Some areas & Yes & Some areas & Some areas \\
\hline Serbia & $6,963,800$ & 43.7 & Public & 7.0 & Some areas & Yes & No & Some areas \\
\hline Slovakia & $5,450,400$ & 26.6 & Public and private & 13.8 & None & Yes & Some areas & Some areas \\
\hline Slovenia & $2,080,900$ & & Public & 5.3 & All areas & Yes & Some areas & Some areas \\
\hline Spain & $46,934,600$ & & Public & 4.9 & Some areas & Yes & No & Some areas \\
\hline Sweden & $10,230,200$ & 97.7 & Public and private & 7.2 & Some areas & Yes & Some areas & Some areas \\
\hline Switzerland & $8,542,300$ & 58.5 & Public and private & 11.9 & Some areas & Yes & Some areas & All areas \\
\hline United Kingdom ${ }^{a}$ & $63,298,819$ & & Public & & Some areas & Yes & Some areas & Some areas \\
\hline
\end{tabular}

For country population official numbers from EU were used. (eurpoa.eu)

Abbreviations: EMS Emergency Medical Services, PCI Percutaneous Coronary Intervention, "Cardiac arrest hospitals" - hospitals capable of providing all of the following post-resuscitation interventions: 24/7 primary $\mathrm{PCl}$, targeted temperature management and neuro-prognostication

anited Kingdom excluding Wales

they did not operate HEMS. Denmark, the Netherlands, Norway, Portugal, Slovakia, and Switzerland reported having 24/7 HEMS availability in all areas (Fig. 3).

In 18 countries there were established first responder systems (where volunteers were alerted to OHCA by the dispatch centre) in some or all areas. Countries that were reported not to have first responder systems were Albania, Belgium, Cyprus, Finland, Greece, Poland, Portugal, Serbia and Slovakia (no information received about Italy). In eight countries, volunteers were reported to staff ambulances in the EMS (i.e. Austria, Belgium, Germany, Hungary, Italy, Luxembourg, Portugal and Romania).

\section{Dispatch characteristics}

The number of dispatch centres per million population ranged from 3.3 in Germany to 0.3 in Albania. Dispatch centres were part of the EMS in 18 countries, while four countries had some dispatch centres as part of the EMS. It was reported that all countries, with the exception of Serbia, operated a standardised dispatch protocol in all or some of the country (no data available for Greece). Dispatch-assisted Cardio Pulmonary Resuscitation (DACPR) instructions were offered in all countries except Greece, but a standardised DA-CPR protocol was not reported to be in use in Poland and Serbia. The type of DA-CPR that was offered was compressions only in ten 


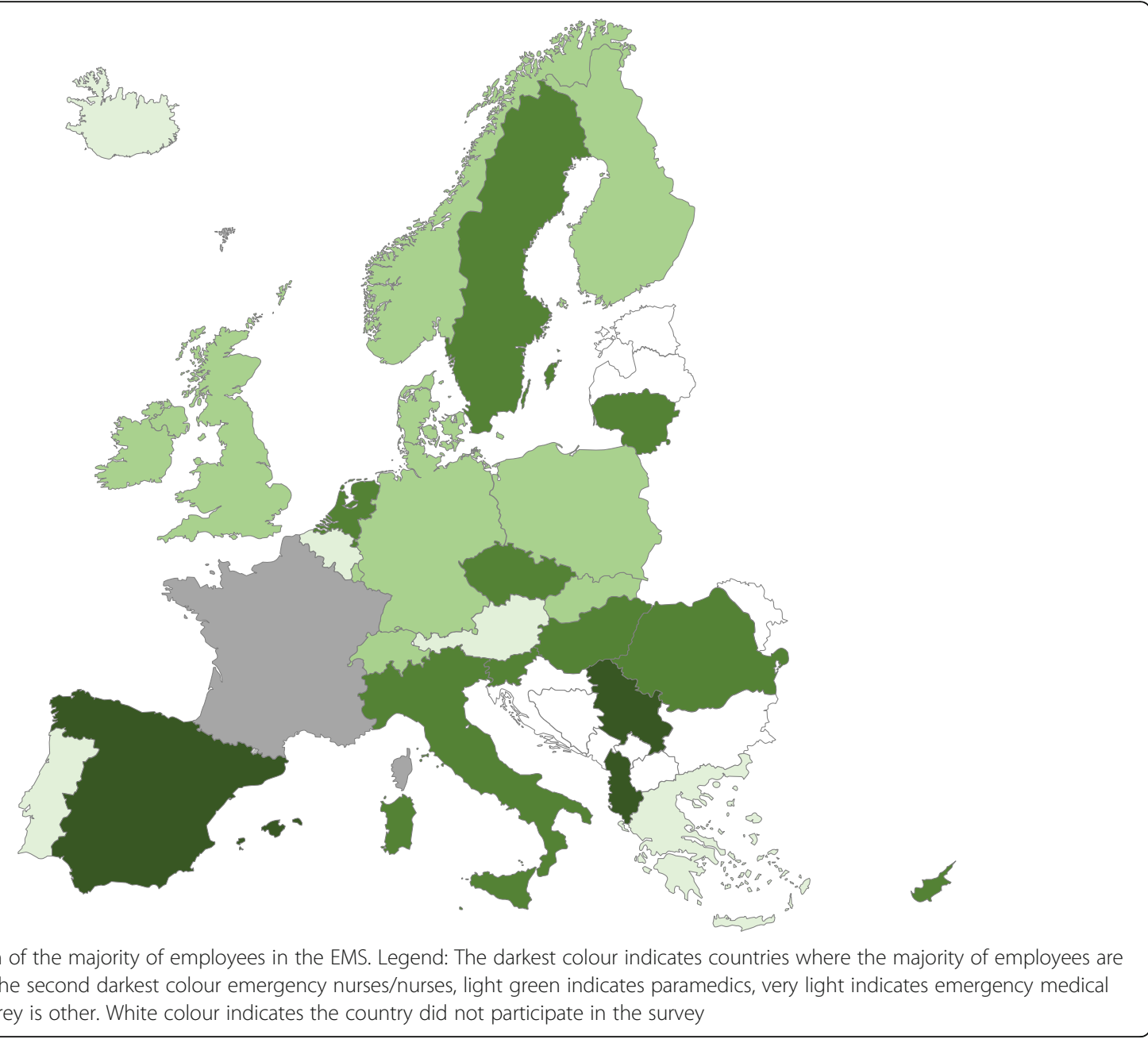

countries, situation dependent in 15 countries and full CPR with compression and ventilation in two countries. Dynamic deployment, meaning sending the nearest available ambulance/EMS resource, was reported in all countries. However, this was only in some areas of Germany, Romania, Serbia, Slovenia, Spain, Switzerland and the United Kingdom. In 21 countries there were registries of publicly available Automated External Defibrillators (AED) in at least some areas (see Table 3).

\section{On-scene management of out-of-hospital cardiac arrest by Emergency Medical Services}

Team training in CPR involving all EMS personnel was reported in 27 countries, but only 12 countries had this in all areas. Defibrillators were available in all EMS vehicles dispatched to OHCA, with the exception of Albania. Real-time CPR performance data was collected for feedback and debriefing purposes in 17 countries, but used in all areas in Cyprus only. Mechanical CPR was used in 24 countries, and transport with ongoing CPR was permitted in all countries except Luxembourg. However, 23 respondents described specific circumstances in which transport with ongoing CPR may be considered. Eighteen countries were reported to use thrombolysis in $\mathrm{OHCA}$. Availability of more advanced resuscitation interventions on-scene was limited, with extracorporeal membrane oxygenation (ECMO) reported as being used in five countries (France, Germany, Italy, Poland and Portugal), and resuscitative endovascular balloon occlusion of the aorta (REBOA) reported in three countries only (Germany, Italy, and Norway) On-scene management of OHCA is presented in Table 4.

\section{Cardiac arrest registries}

Six countries reported having an OHCA registry with full population coverage (Denmark, Ireland, Norway, Portugal, Sweden and Switzerland), while partial coverage was described for 14 countries. Seven countries were reported not to have a registry (data not available for Albania) (Fig. 4). Of the 20 countries reported to have full or partial registries, information on the types of outcome data collected was limited, and only Italy reported 
Table 2 Ambulance service characteristics - training and occupation of EMS ambulance personnel

\begin{tabular}{|c|c|c|c|c|c|c|c|}
\hline \multirow[t]{2}{*}{ Country } & \multirow{2}{*}{$\begin{array}{l}\text { Ambulance } \\
\text { personnel } \\
\text { ALS trained? }\end{array}$} & \multirow{2}{*}{$\begin{array}{l}\text { What is the } \\
\text { occupation } \\
\text { of the majority } \\
\text { of EMS personnel? }\end{array}$} & \multirow{2}{*}{$\begin{array}{l}\text { Do physicians } \\
\text { provide patient } \\
\text { care as part of } \\
\text { EMS? }\end{array}$} & \multicolumn{4}{|c|}{$\begin{array}{l}\text { Can ALS trained ambulance personnel perform the following } \\
\text { interventions without a physician present on scene? }\end{array}$} \\
\hline & & & & $\begin{array}{l}\text { Secure airways with } \\
\text { supraglottic or } \\
\text { endotracheal tubes }\end{array}$ & $\begin{array}{l}\text { Intravenous or } \\
\text { intraosseous drug } \\
\text { therapy }\end{array}$ & $\begin{array}{l}\text { Manual } \\
\text { defibrillation }\end{array}$ & $\begin{array}{l}\text { Semi-automatic } \\
\text { defibrillation }\end{array}$ \\
\hline Albania & Some & $\begin{array}{l}\text { Emergency } \\
\text { physician }\end{array}$ & Sometimes & No & Yes & Yes & Yes \\
\hline Austria & All & EMT & Routinely & Yes & Yes & No & Yes \\
\hline Belgium & Some & EMT & Routinely & No & No & No & Yes \\
\hline Cyprus & All & $\begin{array}{l}\text { Emergency nurse / } \\
\text { nurse }\end{array}$ & No & Yes & Yes & Yes & Yes \\
\hline $\begin{array}{l}\text { Czech } \\
\text { Republic }\end{array}$ & Some & $\begin{array}{l}\text { Emergency nurse / } \\
\text { nurse }\end{array}$ & Routinely & Yes & Yes & Yes & Yes \\
\hline Denmark & All & Paramedic & Routinely & Yes & Yes & Yes & Yes \\
\hline Finland & Some & Paramedic & Routinely & Yes & Yes & Yes & Yes \\
\hline France & Some & Other & Routinely & Yes & Yes & Yes & Yes \\
\hline Germany & All & Paramedic & Routinely & Yes & Yes & Yes & Yes \\
\hline Greece & Some & EMT & Sometimes & No & No & No & No \\
\hline Hungary & Some & $\begin{array}{l}\text { Emergency nurse / } \\
\text { nurse }\end{array}$ & Routinely & Yes & Yes & Yes & Yes \\
\hline Iceland & Some & EMT & Sometimes & Yes & Yes & Yes & Yes \\
\hline Ireland & All & Paramedic & Sometimes & Yes & Yes & Yes & Yes \\
\hline Italy & Some & $\begin{array}{l}\text { Emergency nurse / } \\
\text { nurse }\end{array}$ & Routinely & Yes & Yes & No & Yes \\
\hline Lithuania & Some & $\begin{array}{l}\text { Emergency nurse / } \\
\text { nurse }\end{array}$ & Sometimes & Yes & Yes & Yes & Yes \\
\hline Luxembourg & Some & Paramedic & Routinely & Yes & No & No & Yes \\
\hline Netherlands & All & $\begin{array}{l}\text { Emergency nurse / } \\
\text { nurse }\end{array}$ & Sometimes & Yes & Yes & Yes & Yes \\
\hline Norway & All & Paramedic & Sometimes & Yes & Yes & Yes & Yes \\
\hline Poland & All & Paramedic & Sometimes & Yes & Yes & Yes & Yes \\
\hline Portugal & Some & EMT & Routinely & Yes & Yes & No & Yes \\
\hline Romania & Some & $\begin{array}{l}\text { Emergency nurse / } \\
\text { nurse }\end{array}$ & Sometimes & Yes & Yes & Yes & Yes \\
\hline Serbia & Some & $\begin{array}{l}\text { Emergency } \\
\text { physician }\end{array}$ & Routinely & No & No & No & No \\
\hline Slovakia & All & Paramedic & Routinely & Yes & Yes & Yes & Yes \\
\hline Slovenia & All & $\begin{array}{l}\text { Emergency nurse / } \\
\text { nurse }\end{array}$ & Routinely & Yes & Yes & Yes & Yes \\
\hline Spain & All & $\begin{array}{l}\text { Emergency } \\
\text { physician }\end{array}$ & Routinely & No & Yes & Yes & Yes \\
\hline Sweden & All & $\begin{array}{l}\text { Emergency nurse / } \\
\text { nurse }\end{array}$ & Sometimes & Yes & Yes & Yes & Yes \\
\hline Switzerland & All & Paramedic & Routinely & Yes & Yes & Yes & Yes \\
\hline $\begin{array}{l}\text { United } \\
\text { Kingdom }\end{array}$ & Some & Paramedic & Sometimes & Yes & Yes & Yes & Yes \\
\hline
\end{tabular}

The answers are for the entire country which means that the answers "Some" and "Sometimes" indicate this is not implemented in all EMS services in the entire country

Abbreviations: EMS Emergency Medical Services, EMT Emergency Medical Technician, ALS - Advanced Life Support

a United Kingdom excluding Wales 


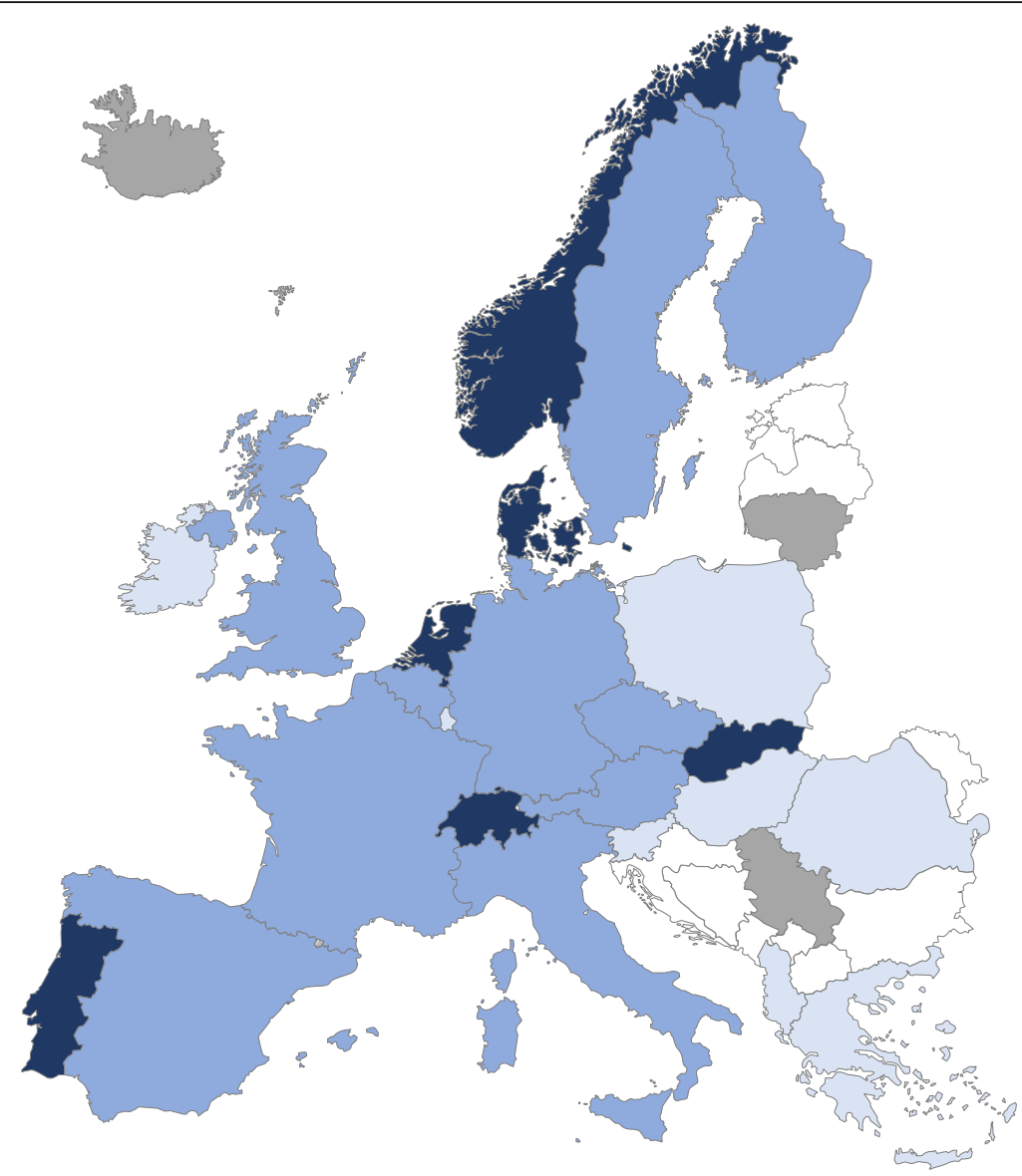

Fig. 3 Availability of Helicopter Emergency Medical Services. Legend: Dark blue indicates HEMS 24/7 in all of the country, medium blue indicates HEMS $24 / 7$ in some areas, light blue indicates HEMS but not 24/7 and grey indicates no HEMS. White colour indicates the country did not participate in the survey

collecting all outcome variable types, albeit only in some areas of the country (see Table 5). Information in registries about the patients' neurological status at discharge was available in 13 registries, but follow-up after discharge and the patients reported quality of life was limited to data collection in some areas of seven countries.

\section{Discussion}

To the best of our knowledge this survey, covering 28 countries, provides the most comprehensive overview of EMS systems in Europe to date, particularly with regard to out-of-hospital cardiac arrest. The survey uncovers variations in service characteristics that are not fully explained in relation to total population, population density or geography. Our findings of substantial variation follow the pattern observed when EMS systems have been compared elsewhere [11-14].

There are some baseline characteristics shared by European countries in that the majority have publicly funded EMS systems and hospital bypass protocols for OHCA. However, our results suggest that while total population explained some proportion of variation, there remains large differences in fundamental measures of EMS activity such as EMS missions per 1000 inhabitants, and the capacity to respond to patients in a median of $10 \mathrm{~min}$. Similarly, most countries were reported to have hospitals capable of providing post-resuscitation care as recommended in the ERC resuscitation guidelines 2015 [20], but there were vast differences in the number of hospitals with 24/7 emergency departments per 1 million inhabitants.

Our survey has shown differences in the types of personnel employed as part of the EMS and in the levels and types of interventions that EMS personnel are allowed to carry out independent of physician supervision. Previous studies have demonstrated how differences in EMS organisation may contribute to variation in OHCA survival. A prospective study showed that higher qualification and greater training experience of ambulance personnel contributed to higher OHCA survival across the four participating EMS agencies [21]. Across the ten ROC sites, differences in EMS practice with regard to initiation of resuscitation and transport was found to contribute to variation in OHCA 


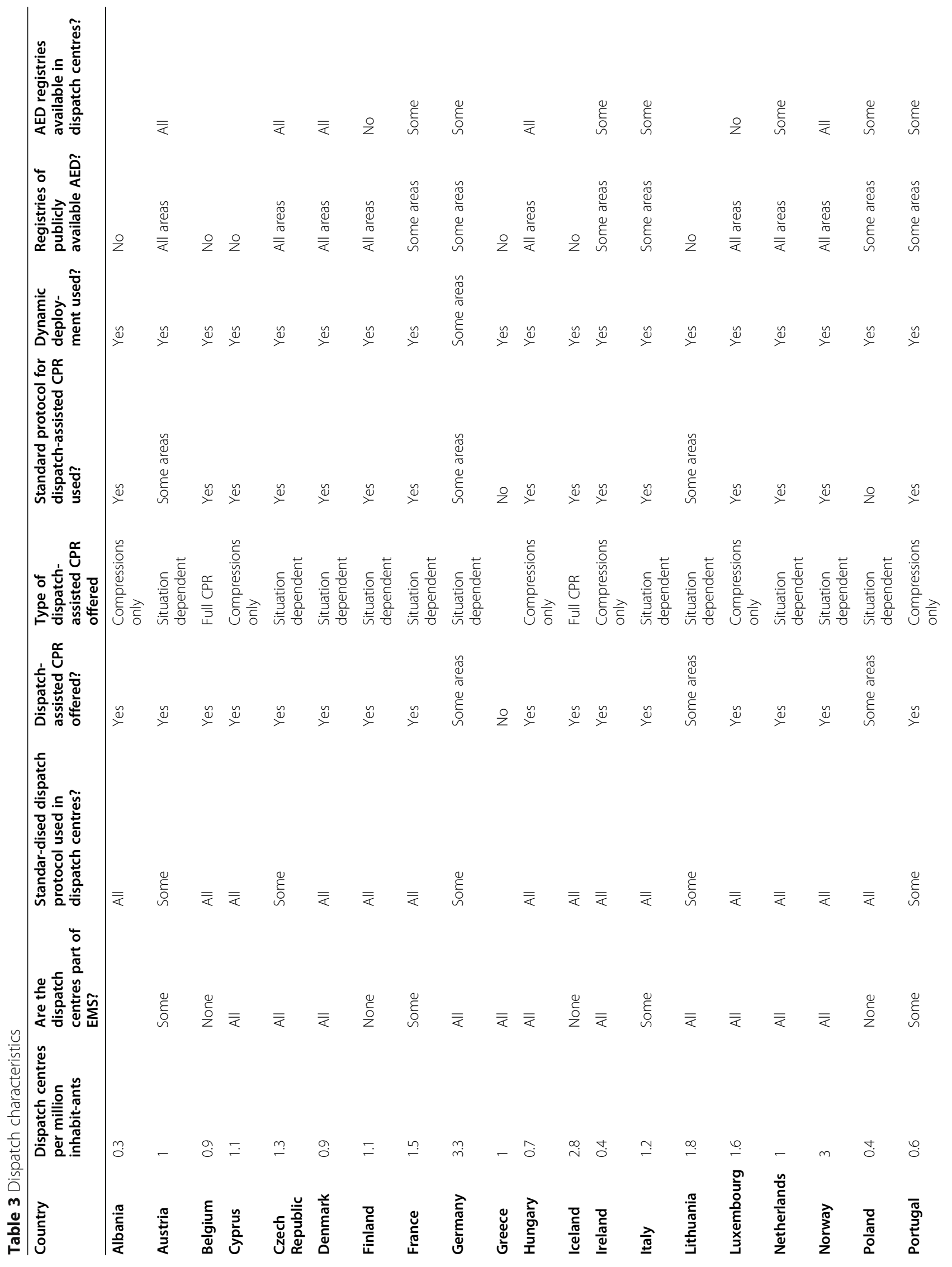




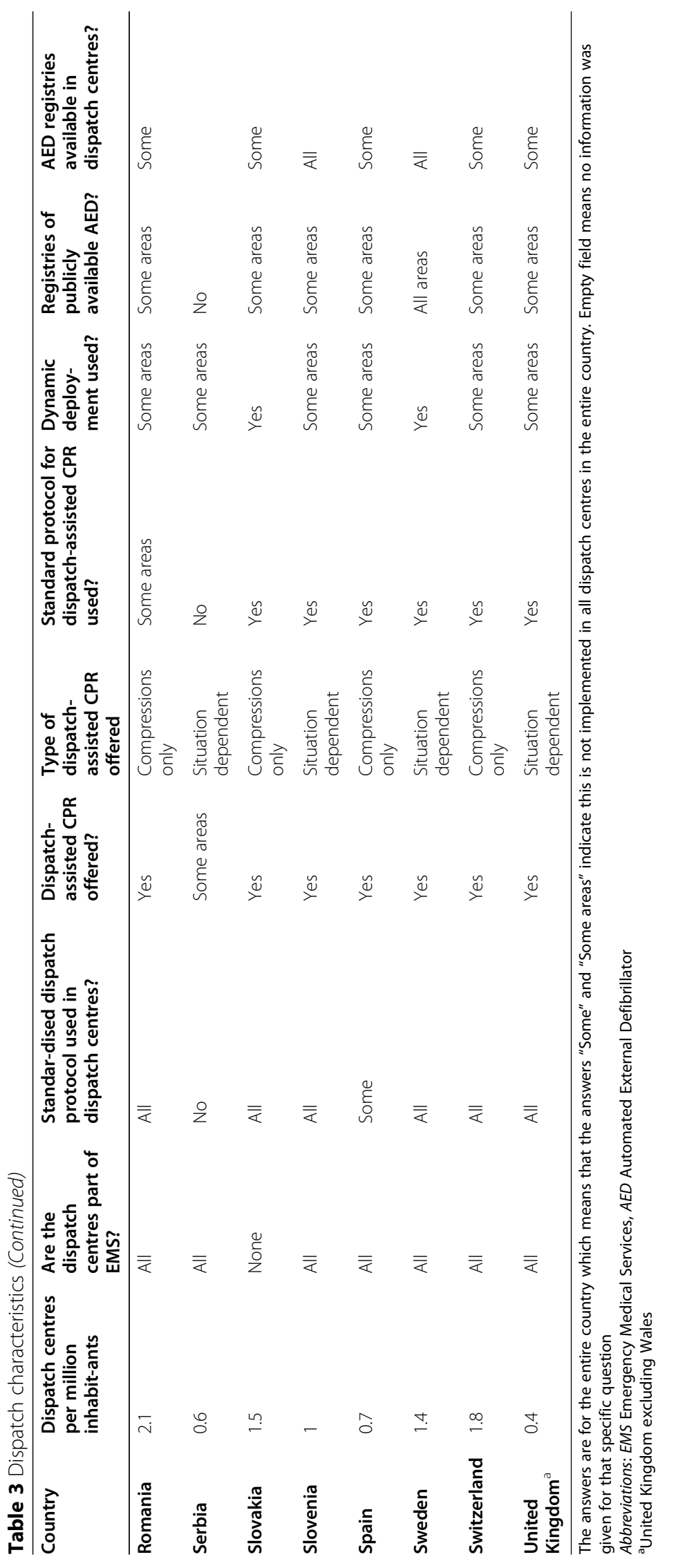


Table 4 On scene management of out-of-hospital cardiac arrest by emergency medical personnel in the participating countries

\begin{tabular}{|c|c|c|c|c|c|c|}
\hline Country & $\begin{array}{l}\text { Is there team training } \\
\text { in CPR involving all } \\
\text { EMS personnel? }\end{array}$ & $\begin{array}{l}\text { Mechanical } \\
\text { CPR used? }\end{array}$ & $\begin{array}{l}\text { Real-time CPR } \\
\text { performance data } \\
\text { collected for } \\
\text { feedback? }\end{array}$ & $\begin{array}{l}\text { Transport with } \\
\text { ongoing CPR } \\
\text { performed? }\end{array}$ & $\begin{array}{l}\text { Defibrillators available in } \\
\text { EMS vehicles dispatched } \\
\text { for cardiac arrest? }\end{array}$ & $\begin{array}{l}\text { Thrombolysis } \\
\text { used in } \\
\text { OHCA? }\end{array}$ \\
\hline Albania & Some areas & No & & Yes & Sometimes & No \\
\hline Austria & Some areas & Some areas & & Yes & Always & Some areas \\
\hline Belgium & Some areas & Some areas & Some areas & Yes & Always & Some areas \\
\hline Cyprus & Yes & All areas & Yes & Yes & Always & No \\
\hline $\begin{array}{l}\text { Czech } \\
\text { Republic }\end{array}$ & Some areas & Some areas & Some areas & Yes & Always & Some areas \\
\hline Denmark & Some areas & Some areas & Some areas & Yes & Always & Yes \\
\hline Finland & Some areas & Some areas & Some areas & Yes & Always & Some areas \\
\hline France & Yes & All areas & & Yes & Always & Some areas \\
\hline Germany & Yes & Some areas & Some areas & Yes & Always & Yes \\
\hline Greece & Yes & No & Some areas & Yes & Always & No \\
\hline Hungary & Some areas & Some areas & No & Yes & Always & No \\
\hline Iceland & Yes & Some areas & Some areas & Yes & Always & No \\
\hline Ireland & Yes & All areas & No & Yes & Always & No \\
\hline Italy & Some areas & Some areas & Some areas & Yes & Always & Some areas \\
\hline Lithuania & Some areas & Some areas & No & Yes & Always & No \\
\hline Netherlands & Yes & Some areas & Some areas & Yes & Always & Yes \\
\hline Norway & Some areas & Some areas & No & Yes & Always & Some areas \\
\hline Poland & Some areas & Some areas & Some areas & Yes & Always & No \\
\hline Portugal & Yes & No & No & Yes & Always & Yes \\
\hline Romania & Yes & Some areas & Some areas & Yes & Always & Some areas \\
\hline Serbia & Yes & Some areas & No & Yes & Always & Yes \\
\hline Luxembourg & No & No & No & No & Always & Some areas \\
\hline Slovakia & Some areas & Some areas & Some areas & Yes & Always & Some areas \\
\hline Slovenia & Yes & Some areas & Some areas & Yes & Always & Yes \\
\hline Spain & Some areas & Some areas & Some areas & Yes & Always & Some areas \\
\hline Sweden & Yes & Some areas & No & Yes & Always & No \\
\hline Switzerland & Some areas & Some areas & Some areas & Yes & Always & \\
\hline $\begin{array}{l}\text { United } \\
\text { Kingdom }\end{array}$ & Some areas & Some areas & Some areas & Yes & Always & Some areas \\
\hline
\end{tabular}

survival [22], and EMS agencies with the highest survival rates more often had: treatment from more than six EMS personnel; a shorter EMS call-response interval; more advanced airway attempts; and treatment from an advancedbasic life support tiered system [23].

Cardiac arrest is highly time-sensitive and after $10 \mathrm{~min}$ with no CPR or defibrillation, the chances of survival are slim. Median response times for urban areas in Europe of under 10 min were achieved in only $32 \%$ of the countries. It is therefore encouraging that our survey has reported that at least 18 European countries have established first responder systems. However, another recent European survey described that many different kinds of first responder systems are used, and also highlighted that regions within countries had different approaches [24]. The introduction of first responder systems is positive, but further layers of difference now need to be considered when explaining variation in outcomes. Of the countries included in our survey, $67 \%$ had all dispatch centres as part of the EMS while 15\% had some dispatch centres as part of the EMS. The size of the country or the total population did not seem to be 


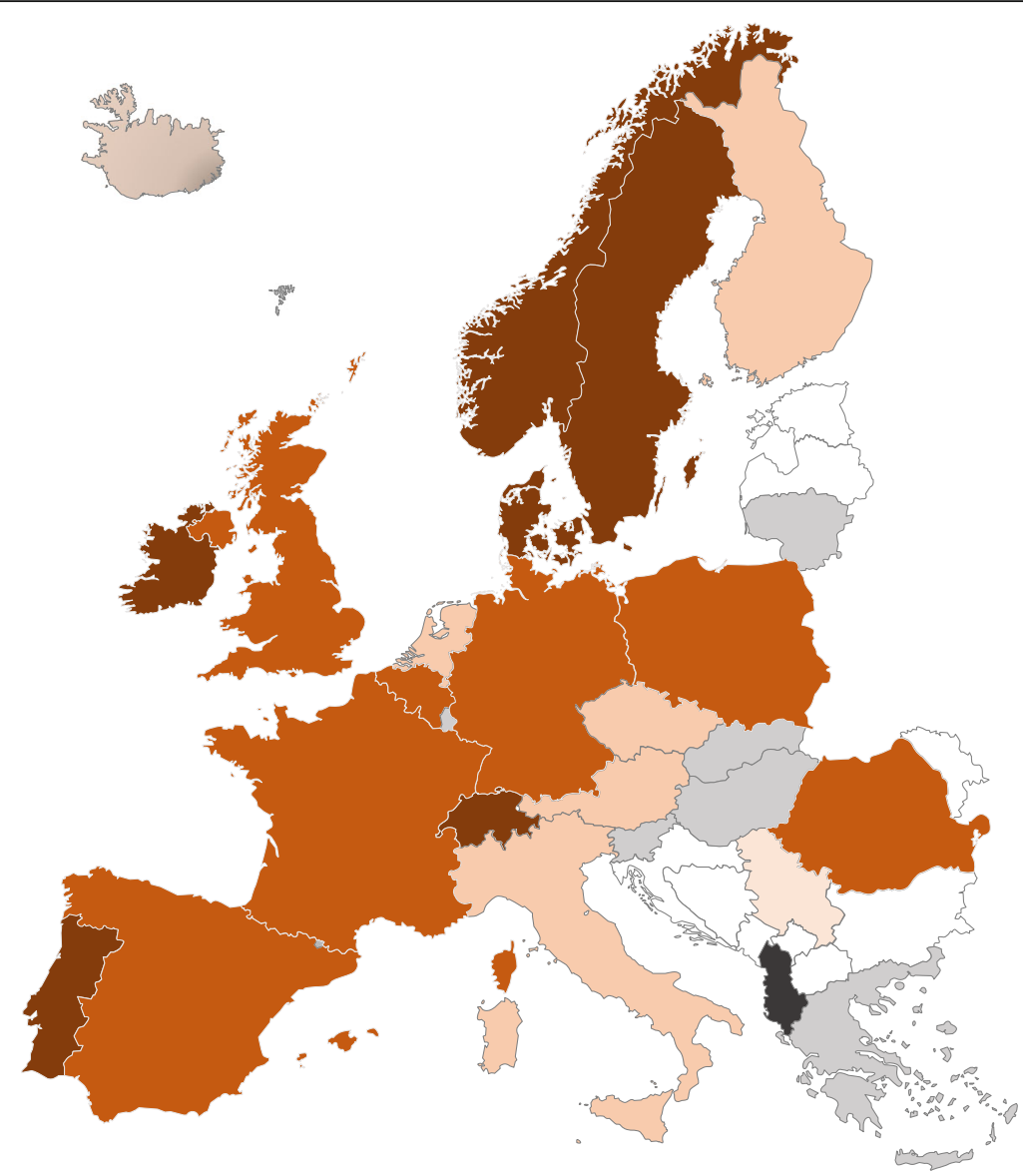

Fig. 4 Out-of-hospital cardiac arrest registries. Legend: The darkest colour indicates a national registry covering all of the country, the second darkest colour indicates a national registry covering parts of the country, medium orange indicates several local registries, light with grey indicates one local registry, grey indicates no local registries and black is unknown. White colour indicates the country did not participate in the survey

the determining factor in the number of dispatch centres. For example, despite differences in population density, Germany and Norway have approximately three dispatch centres per million inhabitants. Similarly, Poland, UK, Ireland and Albania are vastly different in terms of population and land mass, but all have less than 0.5 dispatch centres per million inhabitants. It is important to note that the vast majority of countries reported the use of standardised dispatch protocols and dispatch-assisted CPR instructions. While there was variation in the type of instructions offered, evidence on the type of dispatchassisted CPR instructions that should be offered is still building $[25,26]$. There is increasing evidence of the value of publicly accessible AEDs $[27,28]$, therefore it was encouraging that responses indicated availability of AED registries in 21 countries. Most importantly, the majority of these registries were available in dispatch centres.

Time-to-shock is a critical determinant of survival [29], therefore the availability of defibrillators in EMS vehicles dispatched for cardiac arrest was a positive finding. Evidence on the value of mechanical CPR remains equivocal
[30, 31], which may explain why mechanical CPR was reported to be available in all areas in only three countries. Availability of more advanced prehospital resuscitation interventions was limited, which may also be explained by the current limited evidence to support widespread adoption of these practices. It is of note that most countries permitted transport with ongoing CPR. However, most respondents described very specific circumstances for this practice.

In 2012 the European Parliament published a declaration recommending that all member states adopt common programs for implementing AEDs in public places and training of lay people, adjusting of legislation in order to facilitate CPR and defibrillation by non-medical persons, and organisation of systematic data collection on cardiac arrest for feedback and quality management [32]. Registry data collection in itself is not a guarantee for improved survival, but if core data variables are not available, routine monitoring and surveillance of OHCA outcomes may be difficult. In our survey only six countries reported having a registry with full population coverage and 14 countries reported having partial population coverage. In 


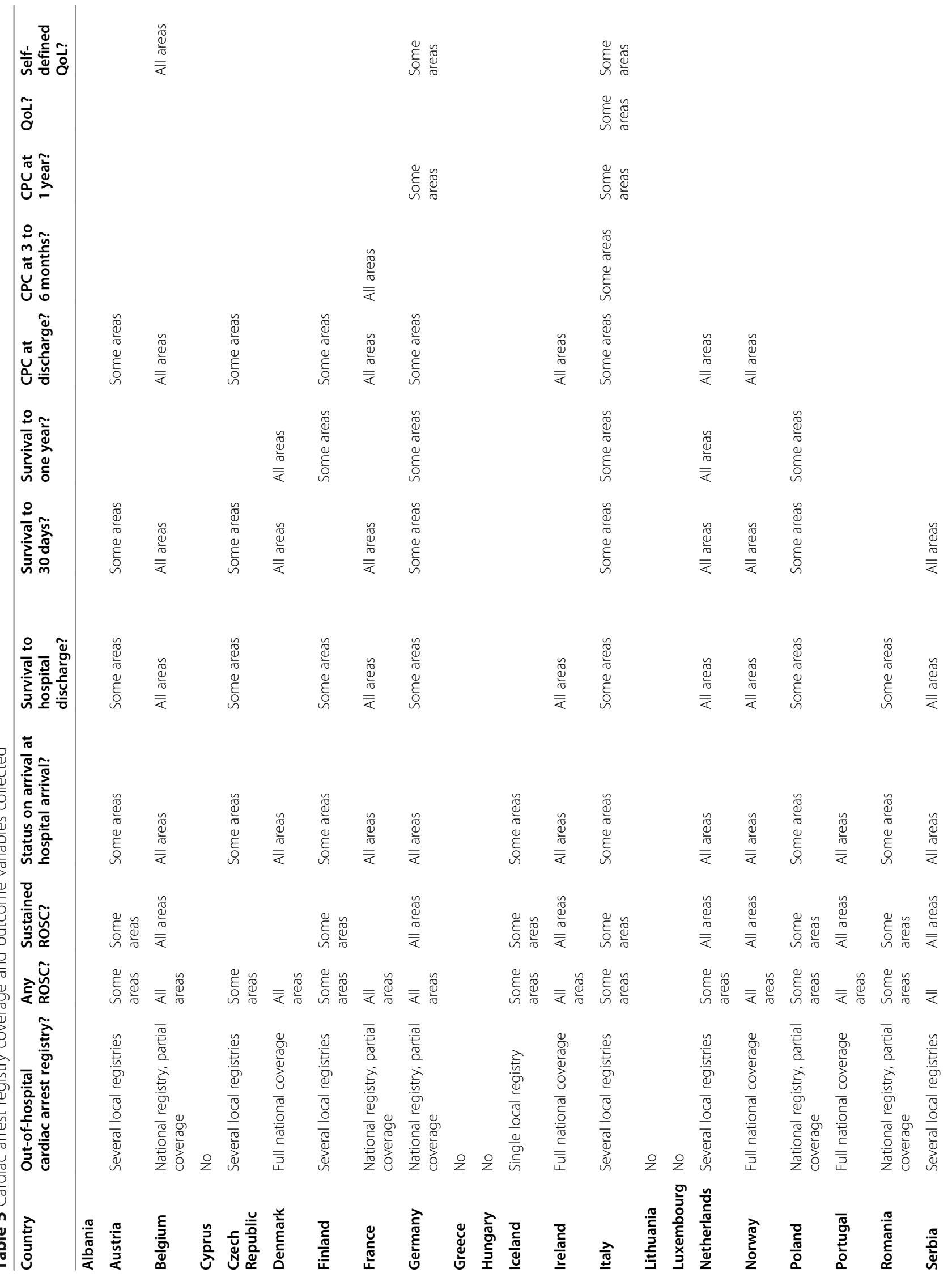




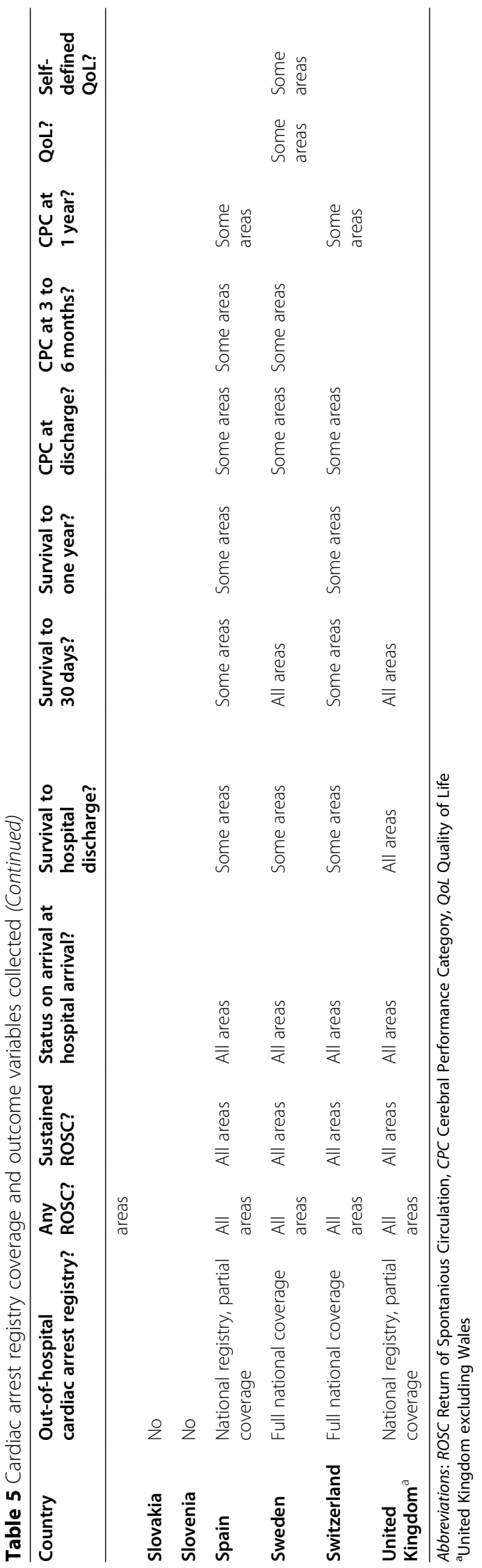


these registries, availability of core outcome variables including ROSC was limited. The establishment of cardiac arrest registries in 20 out of 28 countries is promising, but renewed focus is needed to encourage countries to ensure that outcome data is a core component of data collection, as outcome data is essential to compare results and benchmark against the countries that have achieved high survival rates.

There are a number of limitations to this survey. Firstly, the questionnaire was distributed via an established network, primarily developed for conducting the EuReCa ONE and TWO studies. This network has a specific interest in and responsibility for OHCA management and data collection. While there is a risk of selection bias, it is assumed that respondents have a prior knowledge of the EMS systems in their countries. Additionally, respondents were required to validate their answers with another national expert. Secondly, respondents were required to provide answers about their entire country therefore differences in EMS systems within countries were not the focus of this survey. However, respondents were given the option to answer 'sometimes' or 'in some areas' where appropriate. Finally, the survey was conducted in English but this is not the primary spoken language for most countries that participated. It is therefore possible that there may have been differences in interpretation of questions by different respondents.

This survey has described some of the differences in the EMS systems in Europe and have raised a number of new research questions. In future, research surveys should be set up to look for correlations or associations between variables, and linking the results to outcome after out-of-hospital cardiac arrest and survival after trauma. In addition, future research on EMS systems in Europe should consider using the WHO emergency care system assessment tool.

\section{Conclusion}

Throughout Europe there are significant differences in EMS systems and the response to OHCA. Even for interventions that have been shown to have an effect on survival, implementation across Europe varies. While the impact of EMS system differences is not fully understood, having documented these differences provides the opportunity to adjust for the differences when looking at incidence and survival after OHCA.

\section{Supplementary information}

Supplementary information accompanies this paper at https://doi.org/10. 1186/s13049-020-00798-7.

Additional file 1. EMS survey.

\section{Abbreviations}

OHCA: Out-of-hospital cardiac arrest; ROC: Resuscitation Outcomes Consortium; Aus-ROC: Australian and New Zealand Resuscitation Outcomes
Consortium; PAROS: Pan Asian Resuscitation Outcomes Study; EuReCa: European Registry of Cardiac Arrests; ROSC: Return of spontaneous circulation; EMS: Emergency Medical Services; ERC : European Resuscitation Council; Writing Group: Guidelines 2020 Epidemiology Writing Group; PCl: Percutaneous Coronary Intervention; EMTs: Emergency medical technicians; ALS: Advanced life support; HEMS: Helicopter EMS; DACPR: Dispatch-assisted Cardio Pulmonary Resuscitation; AED: Automated External Defibrillators; ECMO: Extracorporeal membrane oxygenation; REBOA: Resuscitative endovascular balloon occlusion of the aorta

\section{Acknowledgements}

The authors would like to thank all members of the GL2020 epidemiology group and all the respondents.

Writing group:

Jan-Thorsten Gräsne, Berthold Bein, Leo Bossaert, Bernd W. Böttiger, Johan Herlitz, Rolf Lefering, Gisela Lilja, Siobhan Masterson, Fernando Rosell-Ortiz, Gavin D. Perkins, Jan Wnent.

Respondents to the survey:

Sule Akin, Hajriz Alihodzic, Valentine Baert, Marieke Blom, Scott Booth, Roman Burkart, Dave Bywater, Drilon Kamishi, Michael Baubin, Alexei Birkun, Grzegorz Cebula, Diana Cimpoiesu, Giordimaina Christopher, Carlo Clarens, Vitor Hugo Gouveia Correia, Johan Herlitz, Hlynur Höskuldsson, Marios loannides, Asta Krikscionaitiene, Stephanie Leckey, Freddy Lippert, Andrej Markota, Pierre Mols, Eniko Nagy, Nikolaos Nikolao, Fernando Rossell-Ortiz, Violetta Raffay, Ari Salo, Federico Semeraro, Stefan Trenkler, Anatolij Truhláŕ, Jan Wnent and Martin Quinn.

\section{Authors' contributions}

Ingvild Tjelmeland: Conceptualization and design of the work, analysis and interpretation of data, written first drafted and revised the final article, project administration. Siobhan Masterson: Conceptualization and design of the work, analysis and interpretation of data, written first drafted and approved final version. Johan Herlitz: Conceptualization and design of the work, analysis and interpretation of data, written first drafted and approved final version. Jan Wnent: Conceptualization and design of the work, analysis and interpretation of data, written first drafted and approved final version. Leo Bossaert: Conceptualization and design of the work, analysis and interpretation of data, written first drafted and approved final version, supervision. Fernando Rossell Ortiz: Conceptualization and design of the work, analysis and interpretation of data, written first drafted and approved final version. Kristin Alm-Kruse: Analysis and interpretation of data, written first drafted and approved final version. Berthold Bein: Conceptualization and design of the work, analysis and interpretation of data, approved final version. Gisela Lilja: Conceptualization and design of the work, analysis and interpretation of data, written first drafted and approved final version. Jan-

Thorsten Gräsner: Conceptualization and design of the work, analysis and interpretation of data, written first drafted and approved final version, supervision. The author(s) read and approved the final manuscript

\section{Funding}

No funding was received for this study.

\section{Availability of data and materials}

The individual responses to the survey are available from the corresponding author on reasonable request. Consent from all involved participants will be sought before sharing.

Ethics approval and consent to participate

Ethical approval for this study was granted by the Research Ethics Committee of the Christian-Albrechts University of Kiel, Germany (D520/19).

Consent for publication

Not applicable.

\section{Competing interests}

Ingvild Tjelmeland: has nothing to disclose.

Siobhan Masterson: has nothing to disclose.

Johan Herlitz: has nothing to disclose.

Jan Wnent: has no financial COI to be declared. Jan Wnent is member of the steering commitee of the German Resuscitation Registry and member of the EuReCa study managment team. 
Leo Bossaert: has nothing to disclose.

Fernando Rossell Ortiz: has nothing to disclose.

Kristin Alm-Kruse: has nothing to disclose.

Berthold Bein: reports personal fees from Edwards Life Sciences, personal fees from CSL Behring, personal fees from Pharmacosmos, personal fees from Ferrer, personal fees from Cytosorbents, personal fees from TEVA Ratiopharm, outside the submitted work.

Gisela Lilja: has nothing to disclose.

Jan-Thorsten Gräsner: reports personal fees and other from Weinmann: Emergency, personal fees and other from Philips Medical, personal fees and other from Fresenius, personal fees from Bard, personal fees and other from Zoll, outside the submitted work.

\section{Author details}

${ }^{1}$ Institute for Emergency Medicine, University-Hospital Schleswig-Holstein, Arnold-Heller-Str. 3, 24105 Kiel, Germany. ${ }^{2}$ Division of Prehospital Services, Oslo University Hospital, Oslo, Norway. ${ }^{3}$ Faculty of Medicine, Institute of Clinical Medicine, University of Oslo, Oslo, Norway. ${ }^{4}$ The National Ambulance Service Ireland and the National University of Ireland Galway (on behalf of the Out-of-Hospital Cardiac Arrest Register (OHCAR)), Galway, Ireland. ${ }^{5}$ PreHospen - Centre for Prehospital Research, Faculty of Caring Science, Work-Life and Social Welfare, University of Borås, Borås, Sweden. ${ }^{6}$ European Resuscitation Council, Niel, Belgium. ${ }^{7}$ Department of Anesthesiology and Intensive Care Medicine, University-Hospital Schleswig-Holstein, Kiel, Germany. ${ }^{8}$ School of Medicine, University of Namibia, Windhoek, Namibia. ${ }^{9}$ University of Antwerp, Antwerp, Belgium. ${ }^{10}$ Servicio de Urgencias y Emergencias 061 de La Rioja, Logroño, Spain. " Department of Research \& Development, Division of Emergencies and Critical Care, Oslo University Hospital, Oslo, Norway. ${ }^{12}$ Anaesthesiology and Intensive Care Medicine, Asklepios Hospital St. Georg, Hamburg, Germany. ${ }^{13}$ Faculty of Medicine, Semmelweis University, Hamburg, Germany. ${ }^{14}$ Department of Clinical Sciences Lund, Neurology, Lund University, Skåne University Hospital, Lund, Sweden.

Received: 14 May 2020 Accepted: 7 October 2020 Published online: 19 October 2020

\section{References}

1. Zive DM, Schmicker R, Daya M, Kudenchuk P, Nichol G, Rittenberger JC, et al. Survival and variability over time from out of hospital cardiac arrest across large geographically diverse communities participating in the Resuscitation Outcomes Consortium. Resuscitation. 2018;131:74-82.

2. Beck B, Bray J, Cameron P, Smith K, Walker T, Grantham H, et al. Regional variation in the characteristics, incidence and outcomes of out-of-hospital cardiac arrest in Australia and New Zealand: results from the Aus-ROC Epistry. Resuscitation. 2018;126:49-57.

3. Ong MEH, Shin SD, De Souza NNA, Tanaka H, Nishiuchi T, Song KJ, et al. Outcomes for out-of-hospital cardiac arrests across 7 countries in Asia: the Pan Asian Resuscitation Outcomes Study (PAROS). Resuscitation. 2015;96: 100-8.

4. Gräsner J-T, Lefering R, Koster RW, Masterson S, Böttiger BW, Herlitz J, et al. EuReCa ONE; 27 Nations, ONE Europe, ONE Registry. Resuscitation. 2016;105: 188-95.

5. Gräsner J-T, Wnent J, Herlitz J, Perkins GD, Lefering R, Tjelmeland I, et al. Survival after out-of-hospital cardiac arrest in Europe - results of the EuReCa TWO study. Resuscitation. 2020;148:218-26.

6. Perkins GD, Jacobs IG, Nadkarni VM, Berg RA, Bhanji F, Biarent D, et al. Cardiac arrest and cardiopulmonary resuscitation outcome reports: update of the Utstein resuscitation registry templates for out-of-hospital cardiac arrest: a statement for healthcare professionals from a task force of the International Liaison Committee on Resuscitation (American Heart Association, European Resuscitation Council, Australian and New Zealand Council on Resuscitation, Heart and Stroke Foundation of Canada, InterAmerican Heart Foundation, Resuscitation Council of Southern Africa, Resuscitation Council of Asia); and the American Heart Association Emergency Cardiovascular Care Committee and the Council on Cardiopulmonary, Critical Care, Perioperative and Resuscitation. Resuscitation. 2015;96:328-40.

7. Sasson C, Rogers MA, Dahl J, Kellermann AL. Predictors of survival from outof-hospital cardiac arrest: a systematic review and meta-analysis. Circ Cardiovasc Qual Outcomes. 2010;3(1):63-81.
8. Buick JE, Ray JG, Kiss A, Morrison $\sqcup$. The association between neighborhood effects and out-of-hospital cardiac arrest outcomes. Resuscitation. 2016;103:14-9.

9. Rea TD, Cook AJ, Stiell IG, Powell J, Bigham B, Callaway CW, et al. Predicting survival after out-of-hospital cardiac arrest: role of the Utstein data elements. Ann Emerg Med. 2010;55(3):249-57.

10. Dyson K, Brown SP, May S, Smith K, Koster RW, Beesems SG, et al. International variation in survival after out-of-hospital cardiac arrest: $\mathrm{A}$ validation study of the Utstein template. Resuscitation. 2019;138:168-81.

11. Sun KM, Song KJ, Shin SD, Tanaka H, Shaun GE, Chiang WC, et al. Comparison of emergency medical services and trauma care systems among Pan-Asian countries: an international, multicenter, population-based survey. Prehosp Emerg Care. 2017;21(2):242-51.

12. Beck B, Bray JE, Smith K, Walker T, Grantham H, Hein C, et al. Description of the ambulance services participating in the Aus-ROC Australian and New Zealand out-of-hospital cardiac arrest Epistry. Emerg Med Australas. 2016;28(6):673-83.

13. Davis DP, Garberson LA, Andrusiek DL, Hostler D, Daya M, Pirrallo R, et al. A descriptive analysis of emergency medical service systems participating in the resuscitation outcomes consortium (ROC) network. Prehosp Emerg Care. 2007;11(4):369-82.

14. Govindarajan P, Lin L, Landman A, McMullan JT, McNally BF, Crouch AJ, et al. Practice variability among the EMS systems participating in cardiac arrest registry to enhance survival (CARES). Resuscitation. 2012;83(1):76-80.

15. Takei $Y$, Inaba H, Yachida T, Enami M, Goto Y, Ohta K. Analysis of reasons for emergency call delays in Japan in relation to location: high incidence of correctable causes and the impact of delays on patient outcomes. Resuscitation. 2010;81(11):1492-8.

16. Tranberg T, Lippert FK, Christensen EF, Stengaard C, Hjort J, Lassen JF, et al. Distance to invasive heart centre, performance of acute coronary angiography, and angioplasty and associated outcome in out-of-hospital cardiac arrest: a nationwide study. Eur Heart J. 2017;38(21):1645-52.

17. Stieglis R, Zijlstra JA, Riedijk F, Smeekes M, van der Worp WE, Koster RW. AED and text message responders density in residential areas for rapid response in out-of-hospital cardiac arrest. Resuscitation. 2020;150:170-7.

18. Lee $\mathrm{SCL}$, Mao DR, Ng YY, Leong BSH, Supasaovapak J, Gaerlan FJ, et al. Emergency medical dispatch services across Pan-Asian countries: a webbased survey. BMC Emerg Med. 2020;20(1):8.

19. European Union. Eurostat [webpage]. europa.eu: European Union; 2020. Available from: https://europa.eu/european-union/about-eu/figures/living_en.

20. Nolan JP, Soar J, Cariou A, Cronberg T, Moulaert VR, Deakin CD, et al. European Resuscitation Council and European Society of Intensive Care Medicine guidelines for post-resuscitation care 2015: section 5 of the European Resuscitation Council guidelines for resuscitation 2015. Resuscitation. 2015;95:202-22.

21. Fischer M, Kamp J, Riesgo LGC, Robertson-Steel I, Overton J, Ziemann A et al. Comparing emergency medical service systems-a project of the European Emergency Data (EED) project. Resuscitation. 2011;82(3):285-93.

22. Zive D, Koprowicz K, Schmidt T, Stiell I, Sears G, Van Ottingham L, et al. Variation in out-of-hospital cardiac arrest resuscitation and transport practices in the Resuscitation Outcomes Consortium: ROC Epistry-Cardiac Arrest. Resuscitation. 2011;82(3):277-84.

23. Okubo M, Schmicker RH, Wallace DJ, et al. Variation in survival after out-ofhospital cardiac arrest between emergency medical services agencies. JAMA Cardiol. 2018;3(10):989-99.

24. Oving I, Masterson S, Tjelmeland IBM, Jonsson M, Semeraro F, Ringh M, et al. First-response treatment after out-of-hospital cardiac arrest: a survey of current practices across 29 countries in Europe. Scand J Trauma Resusc Emerg Med. 2019;27(1):112.

25. Shibahashi K, Ishida T, Kuwahara Y, Sugiyama K, Hamabe Y. Effects of dispatcher-initiated telephone cardiopulmonary resuscitation after out-ofhospital cardiac arrest: a nationwide, population-based, cohort study. Resuscitation. 2019;144:6-14.

26. Noel L, Jaeger D, Baert V, Debaty G, Genin M, Sadoune S, et al. Effect of bystander CPR initiated by a dispatch centre following out-of-hospital cardiac arrest on 30-day survival: adjusted results from the French National Cardiac Arrest Registry. Resuscitation. 2019;144:91-8.

27. Neves Briard J, de Montigny L, Ross D, de Champlain F, Segal E. Is distance to the nearest registered public automated defibrillator associated with the probability of bystander shock for victims of out-of-hospital cardiac arrest? Prehosp Disaster Med. 2018;33(2):153-9.

28. Kiyohara K, Nitta M, Sato Y, Kojimahara N, Yamaguchi N, Iwami T, et al. Tenyear trends of public-access defibrillation in Japanese school-aged patients 
having neurologically favorable survival after out-of-hospital cardiac arrest. Am J Cardiol. 2018;122(5):890-7.

29. Waalewijn RA, de Vos R, Koster RW. Out-of-hospital cardiac arrests in Amsterdam and its surrounding areas: results from the Amsterdam resuscitation study (ARREST) in Utstein style. Resuscitation. 1998;38(3):157-67.

30. Madsen Hardig B, Lindgren E, Östlund E, Herlitz J, Karlsten R, Rubertsson S. Outcome among VFNT patients in the LINC (LUCAS IN Cardiac arrest) trial - a randomised, controlled trial. Resuscitation. 2017; In press accepted manuscript.

31. Seewald S, Obermaier M, Lefering R, Bohn A, Georgieff M, Muth C-M, et al. Application of mechanical cardiopulmonary resuscitation devices and their value in out-of-hospital cardiac arrest: a retrospective analysis of the German Resuscitation Registry. PLoS One. 2019;14(1):e0208113.

32. European Parliament. Declaration of the European Parliament of 14 June 2012 on establishing a European cardiac arrest awareness week. https://eurlex.europa.eu/legal-content/EN/TXT/?uri=CELEX\%3A52012XP0266. European Parliament; 2012 15.11.2013. Contract No.: 52012XP0266.

\section{Publisher's Note}

Springer Nature remains neutral with regard to jurisdictional claims in published maps and institutional affiliations.

Ready to submit your research? Choose BMC and benefit from:

- fast, convenient online submission

- thorough peer review by experienced researchers in your field

- rapid publication on acceptance

- support for research data, including large and complex data types

- gold Open Access which fosters wider collaboration and increased citations

- maximum visibility for your research: over $100 \mathrm{M}$ website views per year

At $\mathrm{BMC}$, research is always in progress.

Learn more biomedcentral.com/submissions 